\title{
EVALUASI SIMPANG BERSINYAL TAMAN SARI - CIKAPAYANG KOTA BANDUNG DENGAN ANALISIS VISSIM
}

\author{
Yopi Greace Hutahaean $^{[1]}$, Budi Hartanto Susilo ${ }^{[2]}$ \\ ${ }^{[1]}$ Alumni, Program Studi Teknik Sipil, Fakultas Teknik, Universitas Kristen Maranatha \\ Email: yopiegrace@gmail.com \\ ${ }^{[2]}$ Guru Besar, Program Studi Teknik Sipil, Fakultas Teknik, Universitas Kristen Maranatha \\ Jl. Prof. Drg. Soeria Soemantri No. 65 Bandung 40164 \\ Email: budiharsus@yahoo.com
}

\begin{abstract}
ABSTRAK
Simpang Taman Sari - Cikapayang merupakan salah satu simpang di Kota Bandung yang mempunyai permasalahan lalu lintas yaitu kemacetan. Hal tersebut terlihat dari panjang antrean pada lengan lengan simpang Taman Sari - Cikapayang hingga simpang Sulanjana yang kerap kali terjadi pada jam sibuk serta weekend. Saat weekend kemacetan terjadi karena banyaknya mobil yang diparkir disepanjang jalan Cikapayang serta daerah depan Balubur Town Square (Baltos). Untuk meminimalisir tingkat kemacetan, dilakukan penelitian agar diketahui penyebab timbulnya kemacetan dan mengoptimalkan kinerja simpang Taman Sari - Cikapayang. Hal tersebut dilakukan dengan memodelkan simpang menggunakan software VisSim. Pemodelan bertujuan menguraikan kemacetan pada kawasan Baltos sehingga diperoleh suatu solusi alternatif untuk mengoptimalkan kinerja simpang. Hasil evaluasi kinerja lalu lintas di simpang Taman Sari - Cikapayang diperoleh panjang antrean terbesar pada jam sibuk sore hari, terjadi pada pendekat Cikapayang dengan panjang 353 meter dan nilai LoS F. Berdasarkan simulasi, solusi terbaik untuk menyelesaikan masalah panjang antrean serta LoS di kawasan Baltos adalah dengan pelarangan parkir secara tegas pada kawasan Baltos karena dapat mengurangi panjang antrean dan meningkatkan LoS F pada kondisi eksisting menjadi LoS A.
\end{abstract}

Kata kunci: kemacetan, VisSim, panjang antrean, LoS.

\begin{abstract}
Taman Sari - Cikapayang intersection is one of the intersections in Bandung that has traffic problems, namely traffic jams. It can be seen from the length of the long lines at the arms of the Taman SariCikapayang intersection to the Sulanjana intersection which often occurs during rush hour and weekend. Traffic jam occur in the Taman Sari - Cikapayang intersection during weekend because of the large number of cars parked along the Cikapayang road and the front of Balubur Town Square (Baltos) area. To minimize the level of congestion, a study was conducted to determine the causes of congestion and optimize the performance of the Taman Sari - Cikapayang intersection. It could be made by modeling the Intersection using VisSim software. From the results of modeling conducted on VisSim software to describe congestion in the area of Baltos can be obtained an alternative solution to optimize the performance of Taman Sari-Cikapayang intrrsection. The results of the evaluation of traffic performance at Taman Sari - Cikapayang intersection is obtained by the length of the largest queue at rush hour in the afternoon are found in the Cikapayang approach with a length of 353 meters with a LoS F. Based on simulation, the best solution to solve the problem of the length of the queue and LoS in the Baltos area is by banned the parking area on the Baltos area because it can reduce the length of the existing condition queue on the Taman Sari and Cikapayang and can increase LoS F in existing conditions to LoS A.
\end{abstract}


Keywords: jams, VisSim, queue, LoS.

\section{PENDAHULUAN}

\subsection{Latar Belakang}

Sistem lalu lintas yang tertata rapih serta berfungsi dengan baik dapat meningkatkan tingkat kenyamanan pengguna jalan. Permasalahan lalu lintas yang sering terjadi adalah kemacetan serta polusi udara. Kemacetan merupakan salah satu permasalahan di Kota Bandung yang saat ini menjadi kota termacet di Indonesia berdasarkan survei terbaru Asian Development Bank. Kemacetan sering terjadi pada persimpangan dimana terjadi pertemuan dan atau perpotongan ruas jalan sehingga terjadi konflik arus lalu lintas.

Simpang Taman Sari - Cikapayang merupakan salah satu simpang di Kota Bandung yang mempunyai permasalahan lalu lintas yaitu kemacetan. Hal tersebut terlihat dari antrean yang sangat panjang pada lengan - lengan simpang Taman Sari- Cikapayang hingga simpang Sulanjana yang kerap kali terjadi pada jam sibuk serta weekend. Saat weekend, kemacetan terjadi dikarenakan banyaknya mobil yang diparkir disepanjang jalan Cikapayang hingga daerah $u$-turn. Selain itu lajur belok seperti lokasi u-turn yang dilanggar oleh pengguna jalan dapat menyebabkan timbulnya kecelakaan atau hambatan bagi lalu lintas yang bergerak lurus ketika kendaraan tersebut menunggu adanya ruang yang kosong dari lalu lintas yang bergerak dari depan. Pada kawasan Balubur Town Square (Baltos) terjadi kemacetan hingga simpang Sulanjana dikarenakan banyaknya taxi online serta pedagang kaki lima pada daerah drop off Baltos yang menyebabkan panjangnya antrean di kawasan tersebut yang termasuk ke dalam daerah simpang Taman Sari - Cikapayang. Simpang Taman Sari - Cikapayang merupakan simpang empat lengan sehingga memiliki pergerakan konflik yang rumit. Semakin banyak lengan suatu simpang semakin rumit pula konflik yang terjadi pada simpang tersebut.

Penelitian tingkat kemacetan simpang Taman Sari - Cikapayang dilakukan untuk meminimalisir tingat kemacetan, mengetahui penyebab kemacetan serta mengoptimalkan kinerja simpang. Hal tersebut dilakukan dengan memodelkan simpang menggunakan software VisSim. Penggunaan software VisSim membutuhkan data: volume kendaraan, geometri jalan, sirkulasi jalan, rambu dan marka, kecepatan kendaraan. Dari hasil pemodelan pada software VisSim untuk menguraikan kemacetan pada kawasan Baltos sesuai dengan kondisi lapangan dapat diperoleh solusi alternatif untuk mengoptimalkan kinerja simpang. 


\subsection{Tujuan Penelitian}

1. Mengevaluasi kinerja lalu lintas di simpang Taman Sari dengan menggunakan software VisSim.

2. Mengidentifikasi penyebab kemacetan pada simpang Taman Sari - Cikapayang.

3. Memberikan solusi alternatif untuk meningkatkan kinerja operasi simpang Taman Sari Cikapayang.

\subsection{Ruang Lingkup Penelitian}

1. Lokasi penelitian: simpang Taman Sari-Cikapayang.

2. Survei lapangan yang dilakukan terdiri atas: survei geometri; survei volume kendaraan; survei sirkulasi jalan; survei panjang antrean.

3. Jenis kendaraan yang dihitung: sepeda motor (MC); kendaraan ringan (LV); kendaraan umum $(\mathrm{KU})$.

4. Solusi alternatif:

a. optimasi waktu sinyal di simpang Taman Sari - Cikapayang;

b. pelarangan parkir.

\subsection{Metodologi Penelitian}

\subsubsection{Lokasi Penelitian}

Simpang Taman Sari - Cikapayang yang terletak pada kawasan Balubur Town Square. Gambar 1 adalah lokasi penelitian dengan lengan - lengan simpang. 


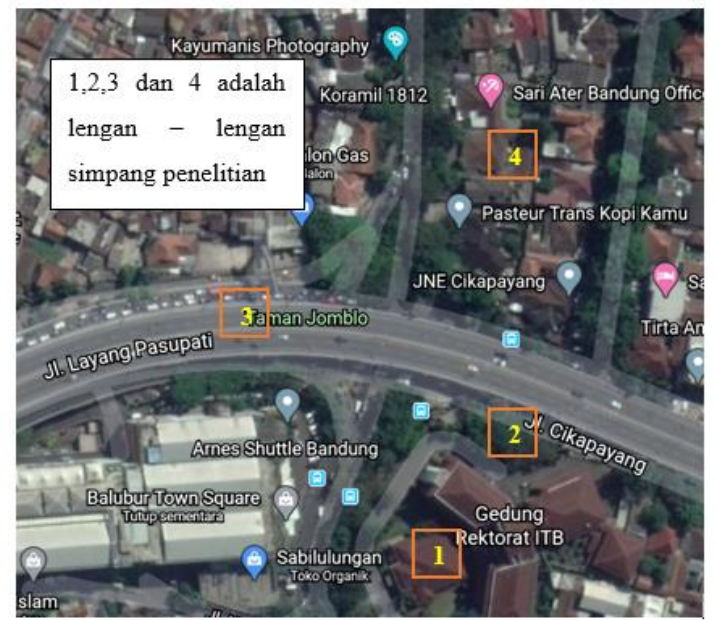

Gambar 1 Lokasi Penelitian

(Google Earth, 2020)

\subsubsection{Teknik Pengumpulan Data}

Data penelitian yang digunakan adalah data observasi pada masa pandemi Covid-19 yang berpengaruh pada berkurangnya volume lalu lintas. Data penguraian kemacetan pada kawasan Balubur Town Squre, meliputi:

1. Data Observasi

Observasi di lapangan menghasilkan data primer meliputi: geometri simpang, volume lalu lintas, panjang antrean dan waktu siklus lampu lalu lintas.

2. Data Sekunder

Diperoleh dari peta satelit Google Earth dan peta jaringan jalan berikut peta kawasan yang diteliti.

Proses pengambilan data:

1. Survei geometri jalan

Data geometri jalan diperoleh pada tanggal 8 Febuari 2020 pada jam 23.00, dilakukan dengan cara mengukur dimensi dari masing - masing jalan menggunakan meteran rol.

2. Survei volume lalu lintas

Dilakukan selama lima belas menit pada hari Sabtu, 15 Febuari 2020 pada jam sibuk, yaitu sore hari pukul 16.30 - 16.45 WIB. Data volume lalu lintas pada tiap - tiap pendekat diperoleh dengan cara menentukan titik - titik pengamatan dan menghitung volume kendaraan pada tiap - tiap ruas jalan dengan menggunakan aplikasi mcounter.

3. Survei panjang antrean

Dilakukan pada hari Sabtu, 15 Febuari 2020 yaitu sore hari pukul 16.00 - 16.45 WIB. Data panjang antrean diperoleh dengan menghitung jumlah antrean kendaraan dari awal 
antrean hingga ujung antrean. Diasumsikan panjang kendaraan adalah 6 meter. Panjang kendaraan diperoleh dengan cara mengalikan jumlah antrean kendaraan dengan panjang antrean.

4. Survei sirkulasi lalu lintas

Dilakukan pada hari Sabtu, 15 Febuari 2020 yaitu sore hari pukul 16.00 WIB. Survei ini dilakukan untuk mengetahui sirkulasi jalan di simpang Taman Sari - Cikapayang, hal ini dikarenakan adanya larangan - larangan seperti belok kiri pada daerah simpang.

5. Survei waktu siklus lampu lalu lintas

Survei waktu siklus dilakukan dengan menggunakan stopwatch dan menghitung durasi apill.

\subsubsection{Tahapan Penelitian}

Dimulai dengan tinjauan pustaka kemudian dilakukan pengumpulan data primer: geometri disekitar simpang Taman Sari - Cikapayang; volume lalu lintas; panjang antrean; waktu siklus lampu lalu lintas. Selanjutnya melakukan pengumpulan data sekunder, yaitu peta citra satelit Google Earh. Data tersebut diolah terlebih dahulu dan di input ke software VisSim sehingga masalah di lapangan dapat divisualisasikan ke dalam software VisSim. Setelah kondisi eksisting divisualisasikan, untuk pemecahan permasalahan dilakukan pemodelan untuk memperoleh solusi alternatif yang tepat. Secara skema seperti Gambar 2.

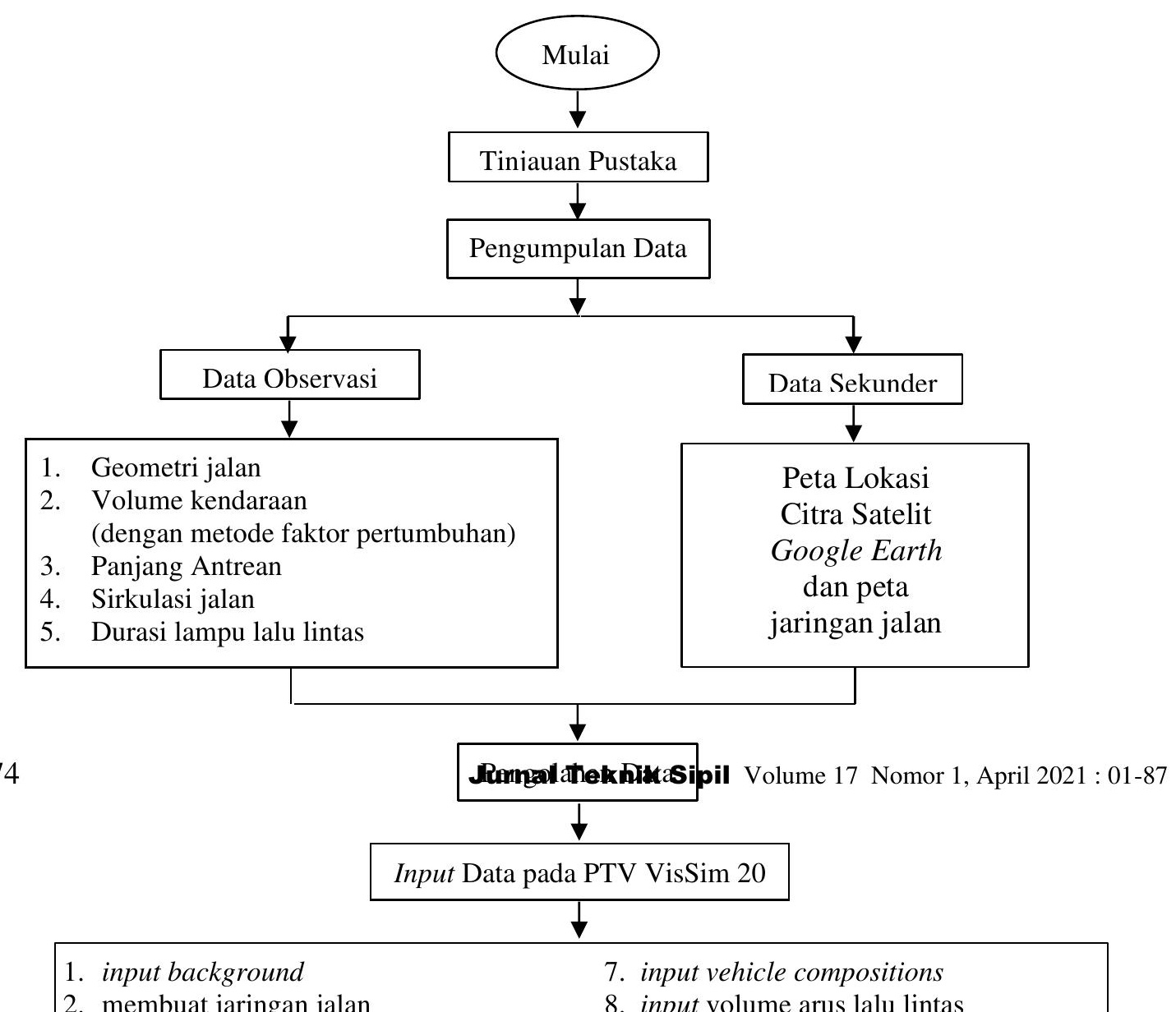




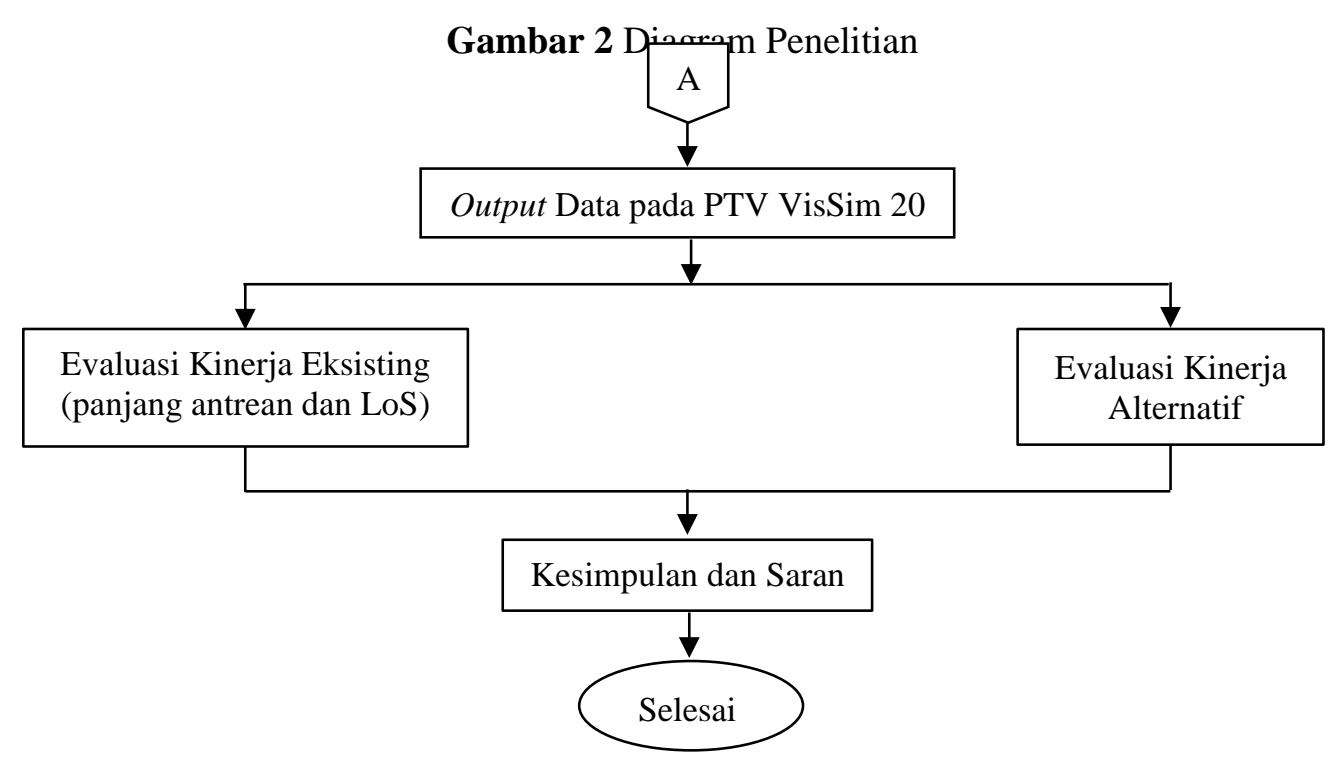

Gambar 2 Diagram Penelitian (Lanjutan)

\section{TINJAUAN PUSTAKA}

\subsection{Karakteristik Arus Lalu Lintas}

Arus lalu lintas merupakan sebuah proses stokastik, yang mempunyai dua variasi acak yaitu karakteristik kendaraan dan pengemudi serta interaksi diantara keduanya (Khisty and Lall, 2006). Terdapat tiga parameter utama lalu lintas:

1. Volume lalu lintas adalah jumlah kendaraan yang lewat pada satu titik pengamatan atau ruas jalan dalam suatu satuan waktu pada setiap periode yang dipilih (Susilo, 2015). 
2. Kecepatan adalah perpindahan kendaraan pada suatu jalan dalam periode waktu tertentu, dengan satuan $\mathrm{km} / \mathrm{jam}, \mathrm{m} / \mathrm{det}$, atau $\mathrm{m} / \mathrm{menit}$. Kecepatan tersebut dipengaruhi oleh karakteristik geometrik, kondisi lalu lintas, waktu, tempat, lingkungan, dan pengemudi (Susilo, 2015).

3. Kepadatan lalu lintas adalah jumlah kendaraan yang menempati panjang jalan yang diamati tersebut (Susilo, 2015).

\subsection{Hubungan Antara Volume, Kecepatan dan Kepadatan}

Menurut Tamin (2000) dan Susilo (2015) karakteristik volume, kecepatan dan kepadatan dapat dipelajari dengan suatu hubungan matematik seperti Persamaan 1 dan Gambar 3:

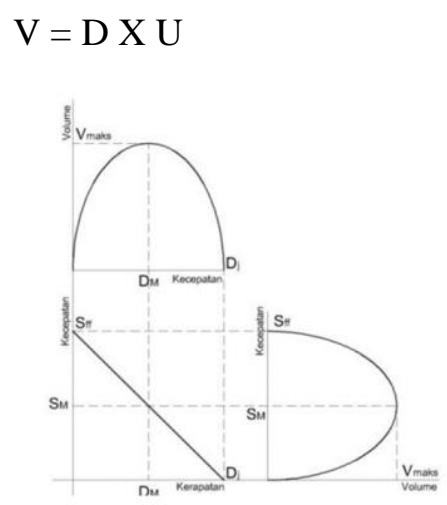

Gambar 3 Hubungan Matematis Antar Volume, Kecepatan dan Kepadatan (Tamin, 2000)

\subsection{Simpang Bersinyal}

Persimpangan sebidang adalah pertemuan dan atau perpotongan ruas jalan sehingga terjadi konflik arus lalu lintas.

Dalam permasalahan simpang ber - APIL (Alat Pemberi Isyarat Lalu Lintas) terdapat beberapa defenisi umum traffic light di antaranya:

a. Fase (phase stage)

Dalam pengaturan lalu lintas pada persimpangan yang berupa konflik antara arus kendaraan, dapat dilakukan dengan pemisahan waktu. Pengaturan pemisahan arus lalu lintas disebut fase (phase). Fase merupakan bagian dari siklus sinyal dengan lampu hijau disediakan bagi kombinasi tertentu dari gerakan lalu lintas.

b. Antrean (queue) 
Antrean merupakan jumlah kendaraan yang antre dalam suatu pendekat.

c. Panjang antrean (queue length)

Panjang antrean merupakan panjang antrean kendaraan pada suatu pendekat.

d. Waktu siklus (cycle time)

Waktu siklus merupakan waktu untuk urutan lengkap dari indikasi sinyal.

e. Waktu hijau (green time)

Waktu hijau merupakan waktu nyala lampu hijau dalam suatu pendekat.

f. Rasio hijau (green ratio)

Rasio hijau merupakan perbandingan waktu hijau dengan waktu siklus dalam suatu pendekat.

g. Waktu merah semua (all red)

Waktu merah semua merupakan waktu sinyal merah menyala secara bersamaan pada sebuah pendekat yang dilayani oleh dua fase sinyal yang berurutan.

h. Waktu antar hijau (intergreen period)

Waktu antar hijau merupakan jumlah antara periode kuning dengan waktu merah semua antara dua fase sinyal yang berurutan.

i. Waktu hilang (lost time)

Waktu hilang merupakan jumlah semua periode antar hijau dalam siklus lengkap atau beda antara waktu siklus dengan jumlah waktu hijau dalam semua fase yang berurutan.

j. $\quad$ Derajat kejenuhan (degree of saturation)

Derajat kejenuhan merupakan rasio arus lalu lintas terhadap kapasitas suatu pendekat.

\subsection{Simulasi Simpang Dengan Software VisSim}

Software VisSim adalah sebuah software simulasi yang digunakan untuk rekayasa lalu lintas, perencanaan transportasi, waktu sinyal, serta perencanan kota yang bersifat mikroskopis dalam aliran lalu lintas multi - moda ysng diterjemahkan secara visual dan dikembangkan oleh PTV Planing Transport Verkehr AG (PTV) di Karlshure, Jerman pada tahun 1992. Beberapa parameter yang yang menjadi input pada software VisSim:

1. Vehicle types, yaitu kelompok jenis kendaraan diidentifikasi melalui perilaku fisik dari kendaraan yang serupa.

2. Vehicle classes, yaitu satu atau lebih jenis kendaraan yang digabungkan pada satu kelas kendaraan. 
3. Vehicle categories, yaitu kategori dari kendaraan yang digabungkan berdasarkan pada interaksi kendaraan yang serupa.

4. Vehicle input, yaitu jumlah kendaraan atau volume lalu lintas dalam satuan kend/jam, memasukan data berdasarkan observasi data pada lapangan.

5. Driving behaviour, yaitu perilaku kendaraan berkendara tergantung dari jenis kendaraan dan jenis jalannya.

6. Vehicle composition, yaitu komposisi masing-masing persentase dari beberapa jenis kendaraan yang melewati satu ruas jalan.

\subsection{Tingkat Pelayanan}

Tingkat pelayanan atau Level of Service (LoS) seperti tersaji pada Tabel 1 merupakan pengukuran kuantitatif yang menjabarkan tentang kondisi - kondisi operasional dalam suatu arus lalu lintas. LoS berkaitan dengan kecepatan operasi atau fasilitas jalan, yang tergantung pada perbandingan antara arus terhadap kapasitas.

Tabel 1 Nilai Indikator Tingkat Pelayanan

\begin{tabular}{ccc}
\hline No & Tingkat Pelayanan & Batas Lingkup \\
\hline 1 & LoS A & $0.00-0.19$ \\
2 & LoS B & $0.20-0.44$ \\
3 & LoS C & $0.45-0.74$ \\
4 & LoS D & $0.75-0.84$ \\
5 & LoS E & $0.85-1.00$ \\
6 & LoS F & $>1.00$ \\
\hline
\end{tabular}

Sumber: TRB, 2000

\section{ANALISIS DATA}

\subsection{Data Observasi}

Observasi lapangan termasuk wawancara dilakukan dengan tujuan memperoleh data primer untuk penelitian ini. Data observasi yang diperoleh dijabarkan pada sub bab berikut.

\subsubsection{Data Geometri Jalan}

Geometri jalan meliputi bentuk/ukuran fisik jalan termasuk lebar jalan. Survei geometri jalan dilakukan dengan bantuan alat ukur meteran. Gambar 4 memperlihatkan tampak atas simpang Taman Sari - Cikapayang. 


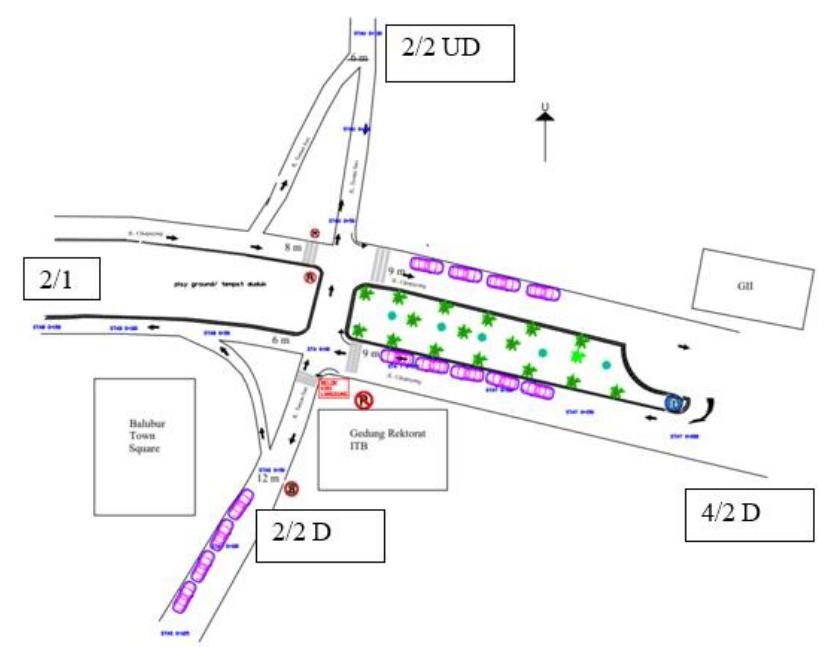

Gambar 4 Denah Geometri dan Simpang Arus Taman Sari - Cikapayang

\subsubsection{Data Siklus Lampu Lalu Lintas}

Durasi waktu siklus lampu lalu lintas yang diambil pada sore hari terdapat pada

Tabel 2.

Tabel 2 Waktu Siklus Lampu Lalu Lintas

\begin{tabular}{cccccccc}
\hline Fase & \multicolumn{1}{c}{ Pendekat } & Letak & $\begin{array}{c}\text { Green } \\
\text { Time }\end{array}$ & Amber & Red & Amber & $\begin{array}{c}\text { Cycle } \\
\text { Time }\end{array}$ \\
\hline 1 & Jl. Taman Sari - ITB & Utara & 48 & 2 & 127 & 2 & 179 \\
\hline 2 & Jl. Taman Sari - Unisba & Selatan & 48 & 2 & 127 & 2 & 179 \\
\hline 3 & Jl. Cikapayang -GII Dago & Timur & 58 & 2 & 117 & 2 & 179 \\
\hline 4 & Jl. Cikapayang - naik pasteur & Barat & 50 & 2 & 125 & 2 & 179 \\
\hline
\end{tabular}

\subsubsection{Data Volume Lalu Lintas}

Survei volume lalu lintas dilakukan pada tiap lajur pendekat simpang. Survei dilakukan pada jam tersibuk yaitu hari Sabtu pukul 16.30-16.45 dengan hasil seperti pada Tabel 3 sampai dengan Tabel 5.

Tabel 3 Volume Lalu Lintas Selama Lima Belas Menit

\begin{tabular}{llcccc}
\hline \multirow{2}{*}{ Lokasi } & \multirow{2}{*}{ Arah } & SM & KR & KU & Total \\
\cline { 3 - 6 } & & \multicolumn{4}{c}{ Kend $(\mathbf{K}) \mathbf{1 5}$ menit } \\
\hline Jl. Taman Sari & Selatan & 292 & 145 & 27 & 464 \\
Jl. Cikapayang & Timur & 212 & 130 & 0 & 342 \\
Jl. Cikapayang & Barat & 210 & 181 & 0 & 391 \\
Jl. Taman Sari & Utara & 176 & 254 & 4 & 434 \\
Jl. Taman Sari & Sulanjana & 78 & 148 & 15 & 241
\end{tabular}




\begin{tabular}{llllll} 
Jl. Taman Sari & Timur & 325 & 64 & 18 & 407 \\
\hline
\end{tabular}

Tabel 4 Volume Lalu Lintas Selama Lima Belas Menit Dalam Satuan SMP

\begin{tabular}{llccc}
\hline \multirow{2}{*}{ Lokasi } & \multirow{2}{*}{ Arah } & SM & KR & KU \\
\cline { 3 - 5 } & & \multicolumn{3}{c}{ SMP/15 menit } \\
\hline Jl. Taman Sari & Selatan & 73 & 145 & 27 \\
Jl. Cikapayang & Timur & 53 & 130 & 0 \\
Jl. Cikapayang & Barat & 52.5 & 181 & 0 \\
Jl. Taman Sari & Utara & 44 & 254 & 4 \\
Jl. Taman Sari & Sulanjana & 19.5 & 148 & 15 \\
Jl. Taman Sari & Timur & 81.25 & 64 & 18 \\
\hline
\end{tabular}

Tabel 5 Volume Lalu Lintas Selama 1 jam

\begin{tabular}{llccccccc}
\hline \multirow{2}{*}{ Jalan } & \multirow{2}{*}{ Arah } & \multicolumn{2}{c}{ SM } & \multicolumn{2}{c}{ KR } & \multicolumn{2}{c}{ KU } & Total \\
& & K/jam & SMP/jam & K/jam & SMP/jam & K/jam & SMP/jam & K/jam \\
\hline Jl. Taman Sari & Selatan & 1168 & 292 & 580 & 580 & 108 & 108 & 1856 \\
Jl. Cikapayang & Timur & 848 & 212 & 520 & 520 & 0 & 0 & 1368 \\
Jl. Cikapayang & Barat & 840 & 210 & 724 & 724 & 0 & 0 & 1564 \\
Jl. Taman Sari & Utara & 704 & 176 & 1016 & 1016 & 16 & 16 & 1736 \\
Jl. Taman Sari & Sulanjana & 312 & 78 & 148 & 148 & 60 & 60 & 520 \\
Jl. Taman Sari & Timur & 325 & 81.25 & 256 & 256 & 72 & 72 & 653 \\
\hline
\end{tabular}

Dari Tabel 5 yaitu volume lalu lintas pada Taman Sari - Cikapayang, dapat diketahui yang menjadi jalan utama/mayor adalah Jalan Taman Sari. Penentuan jalan mayor atau jalan minor dapat dilihat dari lebar jalan atau volume lalu lintas pada jalan tersebut. Volume lalu lintas pada Jalan Taman Sari (Utara - Selatan) sebanyak 1856 kend/jam, sedangkan pada Jalan Cikapayang (Timur- Barat) sebanyak 1564 kend/jam.

Komposisi volume lalu lintas yang melintas pada jalur yang mendekati simpang pada Gambar 5 dibutuhkan untuk diinputkan ke dalam software VisSim dengan tujuan mengatur jumlah arah gerak dari masing-masing jenis kendaraan pada suatu lajur. 


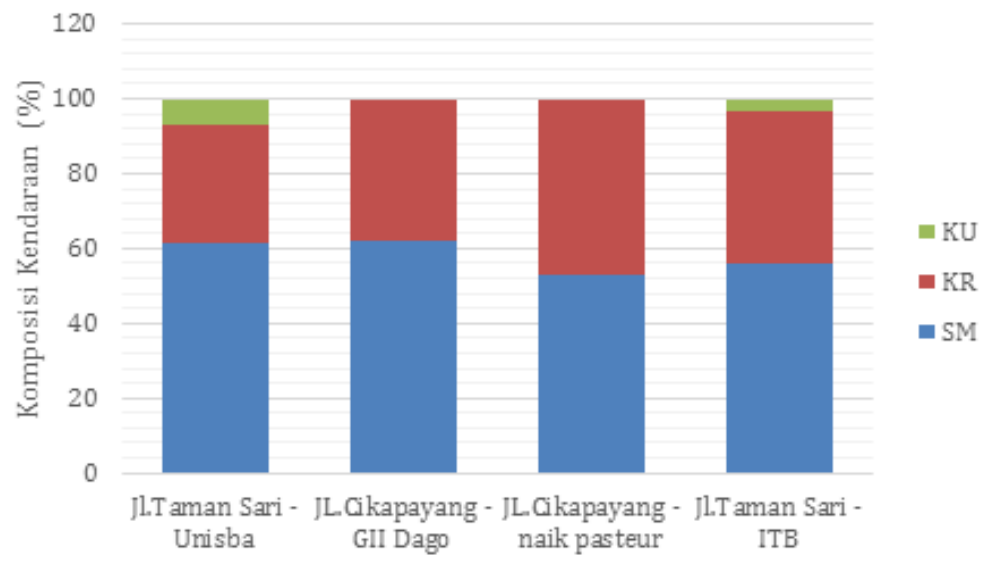

Gambar 5 Komposisi Volume Lalu Lintas

\subsubsection{Data Panjang Antrean}

Data panjang antrean dihitung hingga ujung antrean terakhir. Disemua pendekat simpang panjang antrean berbeda-beda. Data diperoleh dengan cara menghitung panjang antrian kendaraan dari mulut simpang hingga ujung terakhir antrean. Panjang antrean disetiap pendekat dapat dilihat pada Tabel 6 .

Tabel 6 Data Panjang Antrean

\begin{tabular}{clc}
\hline No. & No. Pendekat & Panjang Antrean (m) \\
\hline 1 & Jl. Taman Sari (Selatan) & 210 \\
2 & Jl. Cikapayang (Timur) & 315 \\
3 & Jl. Cikapayang (Barat) & 364 \\
4 & Jl. Taman Sari (Utara) & - \\
5 & Jl. Taman Sari (Sulanjana) & 35 \\
6 & Jl. Taman Sari (Timur) & 161 \\
\hline
\end{tabular}

\subsection{Validasi dan Kalibrasi}

Validasi dan kalibrasi dilakukan untuk pengecekan kesesuaian data di lapangan dan data yang dimodelkan oleh software dengan tujuan agar output software dari pemodelan serupa dengan kondisi eksisting di lapangan. Validasi dan kalibrasi pada penelitian ini yaitu data volume lalu lintas, pada software VisSim adalah data collection result dan panjang antrean yang pada software VisSim adalah queue counter.

Tabel 7 dan Tabel 8 adalah nilai kalibrasi yang dilakukan dengan beberapa kali percobaan agar sesuai dengann kondisi lalu lintas di Indonesia khususnya kota Bandung. 
Nilai kalibrasi kondisi setiap kendaraan seperti SM, KR, KU di Indonesia diperoleh dari beberapa jurnal penelitian mengenai VisSim (Mbuinga, 2020); (Irawan and Putri, 2015); (Pamusti, Herman, and Maulana, 2017); (Ulfah and Purwanti, 2019).

Parameter yang diubah pada software VisSim untuk menyesuaikan model simulasi pada kondisi eksisting di lapangan dan kondisi eksisting pada software, sebagai berikut:

1. observed vehicle in front, yaitu parameter jumlah pergerakkan kendaraan yang diamati oleh pengemudi lain yang ingin melakukan pergerakkan;

2. desired position at free flow, yaitu lajur jalan kendaraan pada saat kondisi arus bebas;

3. overtake on same lane, yaitu menyiap pada lajur manapun;

4. distance standing in meter, yaitu jarak antara kendaraan satu dengan kendaraan yang lain pada saat kondisi berhenti;

5. distance driving in meter, yaitu jarak antara kendaraan satu dengan kendaraan lain pada saat mendekati simpang;

6. average standstill distance, yaitu jarak antara kendaraan yang berurutan pada saat berhenti di simpang;

7. additive part of safety distance, yaitu koefisien penambah jarak aman;

8. multiplicative part of safety distance, yaitu koefisien pengali jarak aman;

9. lane change rule, yaitu perilaku pengemudi saat berkendara;

10. minimum headway, yaitu jarak minimum antara kendaraan satu dengan yang lain pada saat melakukan perubahan lajur;

11. desired lateral position, yaitu posisi kendaraan saat berada dilajur tertentu.

Tabel 7 Nilai Kalibrasi Sepeda Motor

\begin{tabular}{lcc}
\hline \multicolumn{1}{c}{ Parameter } & & Nilai \\
\cline { 2 - 3 } & Sebelum & Sesudah \\
\hline Number of interaction object & 4 & 10 \\
Average standstill distance & 2 & 0,6 \\
Additive part of safety distance $(m)$ & 2 & 0,6 \\
Multiplic Part of safety distance & 3 & 1 \\
Desired position at free flow & Middle of lane & Any \\
Overtake left & Off & On \\
Overtake right & Off & On \\
Distance driving $(m)$ & 1 & 0,4 \\
\hline
\end{tabular}


Tabel 8 Nilai Kalibrasi Mobil dan MPU

\begin{tabular}{lcc}
\hline \multicolumn{1}{c}{ Parameter } & \multicolumn{2}{c}{ Nilai } \\
\cline { 2 - 3 } & Sebelum & Sesudah \\
\hline Average standstill distance & 2 & 0,5 \\
Additive part of safety distance $(m)$ & 2 & 0,1 \\
Multiplic Part of safety distance & 3 & 1 \\
Desired position at free flow & Middle of lane & Any \\
Overtake left & Off & On \\
Overtake right & Off & On \\
Distance driving $(m)$ & 1 & 0,4 \\
\hline
\end{tabular}

Metode terbaik untuk membandingkan data input dan output simulasi adalah dengan menggunakan rumus statistik GEH. GEH singkatan dari Geoffrey E. Havers yaitu nama penemu rumus tersebut. GEH merupakan rumus statistik modifikasi dari Chi-squared dengan menggabungkan perbedaan antara nilai relatif dan mutlak. Rumus GEH pada Persamaan 2 memiliki ketentuan khusus dari nilai error pada Tabel 9.

$\mathrm{GEH}=\sqrt{\frac{(\text { ( pemodelan }-q \text { observasi })^{2}}{0.5(q \text { pemodelan }+q \text { observasi })}}$

Keterangan:

$q$ pemodelan $=$ Nilai output VisSim

$q$ observasi $=$ Nilai hasil observasi di lapangan

Tabel 9 Standar Perhitungan Persamaan GEH

\begin{tabular}{cc}
\hline Nilai GEH & Kesimpulan \\
\hline$<5.0$ & Diterima \\
$5.0 \leq$ GEH $\leq 10.0$ & Peringatan kemungkinan model error atau data buruk \\
GEH $>10.0$ & Ditolak \\
\hline
\end{tabular}

Tabel 10 Validasi Volume Lalu Lintas

\begin{tabular}{lcccc}
\hline \multicolumn{1}{c}{ Pendekat } & $\begin{array}{c}\text { Hasil } \\
\text { Observasi } \\
\text { (kend/jam) }\end{array}$ & $\begin{array}{c}\text { Hasil } \\
\text { Software } \\
\text { (kend/jam) }\end{array}$ & $\begin{array}{c}\text { Nilai } \\
\text { GEH }\end{array}$ & Keterangan \\
\hline Jl. Taman Sari (Selatan) & 1856 & 1859 & 0.07 & Diterima \\
Jl. Cikapayang (Timur) & 1368 & 1460 & 2.45 & Diterima \\
Jl. Cikapayang (Barat) & 1564 & 1494 & 1.79 & Diterima \\
Jl. Taman Sari (Utara) & 1736 & 1630 & 2.58 & Diterima \\
Jl. Taman Sari (Sulanjana) & 520 & 546 & 1.13 & Diterima \\
Jl. Jalan Taman Sari (Timur) & 653 & 654 & 0.04 & Diterima \\
\hline
\end{tabular}




\subsection{Pemodelan Solusi Alternatif 1}

Setelah validasi dan kalibrasi selanjutnya dilakukan pemodelan solusi alternatif rencana dengan tujuan meningkatkan kinerja simpang Taman Sari - Cikapayang. Pemodelan dilakukan dengan mengoptimasikan waktu siklus lampu lalu lintas seperti Gambar 6.

Analisis kinerja persimpangan terkoordinasi dengan optimasi adalah upaya untuk mengoptimalkan waktu siklus pada persimpangan terkoordinasi menggunakan program PTV ViSsim 20. Dilakukan dengan cara trial-error nilai waktu siklus di persimpangan yang ditinjau agar mendapatkan nilai panjang antrean terendah, serta LoS yang sesuai.

\subsection{Pemodelan Solusi Alternatif 2}

Solusi alternatif 2 adalah pelarangan parkir di jalan Cikapayang arah Timur serta pelarangan parkir di Jalan Taman Sari (kawasan depan Baltos), hal tersebut dapat memperkecil lebar jalan, sehingga menyebabkan kemacetan.

Pada kondisi eksisting lebar jalan kawasan Baltos dikurangi sebesar dua meter, sepanjang Jalan Cikapayang arah Timur dikurangi satu meter sebagai penyesuaian. Pemodelan solusi alernatif 2 di software VisSim dilakukan dengan menggambarkan tidak ada kendaraan parkir di sepanjang jalan, sehingga lebar jalan tidak berkurang.

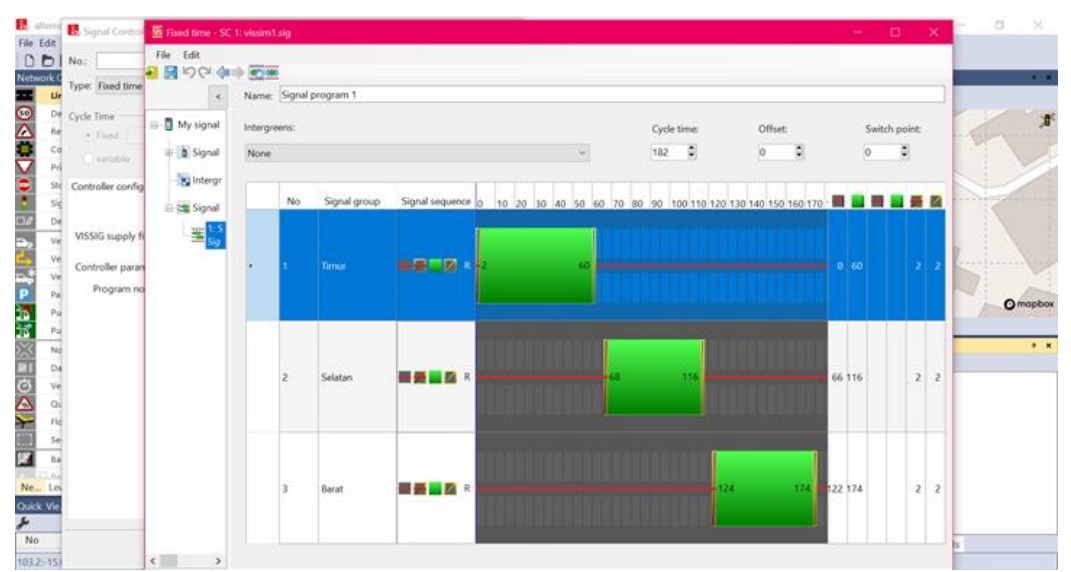

Gambar 6 Pemodelan Waktu Siklus Lampu Lalu Lintas Solusi Alternatif 1

\subsection{Output software VisSim}

Hasil output yang dibandingkan antara kondisi eksisting dan solusi alternatif yaitu panjang antrean dihasilkan dari queue results, serta level of service dihasilkan dari nodes 
results. Tabel 11 menunjukan panjang antrean kondisi eksisting pada software VisSim. Tabel 12 menunjukan nilai LoS kondisi eksisting pada software VisSim.

Tabel 11 Panjang Antrean Pada Kondisi Eksisting Software VisSim

\begin{tabular}{clc}
\hline No. & \multicolumn{1}{c}{ Pendekat } & Panjang Antrean (m) \\
\hline 1. & Jl. Taman Sari (Selatan) & 43,02 \\
2. & Jl. Cikapayang (Timur) & 176,34 \\
3. & Jl. Cikapayang (Barat) & 353 \\
4. & Jl. Taman Sari (Utara) & 104,36 \\
5. & Jl. Taman Sari (Sulanjana) & 19,43 \\
6. & Jl. Jalan Taman Sari (Timur) & 133,23 \\
\hline
\end{tabular}

Tabel 12 LoS Kondisi Eksisting Software VisSim

\begin{tabular}{cll}
\hline No. & \multicolumn{1}{c}{ Movement } & \multicolumn{1}{c}{ LoS (All) } \\
\hline 1. & $1-2-1$ & LoS_E \\
2. & $1-2-6$ & LoS_B \\
3. & $1-3-11$ & LoS_D \\
4. & $1-5-1$ & LoS_F \\
5. & $1-5-4$ & LoS_F \\
6. & $1-5-11$ & LoS_E \\
7. & $1-7-11$ & LoS_D \\
8. & 1 & LoS_E \\
\hline
\end{tabular}

\subsubsection{Panjang Antrean Output Software VisSim}

Solusi alternatif 1 dan alternatif 2 untuk panjang antrean seperti pada Tabel 13.

Tabel 13 Panjang Antrean Pada Solusi Alternatif 1 dan Alternatif 2

\begin{tabular}{clcc}
\hline \multirow{2}{*}{ No. } & \multicolumn{1}{c}{ Nama Pendekat } & Alternatif 1 & Alternatif 2 \\
\cline { 2 - 4 } & \multicolumn{2}{c}{ m } \\
\hline 1. & Jl. Taman Sari (Selatan) & 43,02 & 17,29 \\
2. & Jl. Cikapayang (Timur) & 176,34 & 62,94 \\
3. & Jl. Cikapayang (Barat) & 326,48 & 325,85 \\
4. & Jl. Taman Sari (Utara) & 98,18 & 77,26 \\
5. & Jl. Taman Sari (Sulanjana) & 19,82 & 19,72 \\
6. & Jl. Jalan Taman Sari (Timur) & 133,23 & 133,08 \\
\hline
\end{tabular}

\subsubsection{LoS Output Software VisSim}

Solusi alternatif 1 dan alternatif 2 untuk LoS seperti pada Tabel 14.

Tabel 14 LoS Solusi Alternatif 1 dan Solusi Alternatif 2

\begin{tabular}{cccc}
\hline No. & Movement & LoS Alternatif 1 & LoS Alternatif 2 \\
\hline 1. & $1-2-1$ & LoS_B & LoS_A
\end{tabular}

Evaluasi Simpang Bersinyal Taman Sari - Cikapayang Kota Bandung Dengan Analisis VisSim (Yopi Greace Hutahaean, Budi Hartanto Susilo) 


\begin{tabular}{llll}
2. & $1-2-6$ & LoS_C & LoS_A \\
3. & $1-3-11$ & LoS_A & LoS_A \\
4. $1-5-1$ & LoS_C & LoS_B \\
5. $1-5-4$ & LoS_C & LoS_C \\
6. & $1-5-11$ & LoS_A & LoS_A \\
7. & $1-7-11$ & LoS_A & LoS_A \\
8. & 1 & LoS_C & LoS_A \\
\hline
\end{tabular}

\section{KESIMPULAN DAN SARAN}

\subsection{Kesimpulan}

Berdasarkan hasil analisis yang telah dilakukan, dapat disimpulkan sebagai berikut:

1. Hasil evaluasi kinerja lalu lintas di simpang Taman Sari - Cikapayang melalui simulasi kondisi eksisting pada software VisSim diperoleh antrean terpanjang pada jam sibuk sore hari terjadi pada pendekat Cikapayang dengan panjang 353 meter, dengan nilai LoS E.

2. Hasil identifikasi penyebab timbulnya kemacetan pada simpang Taman Sari Cikapayang adalah karena berkurangnya lebar jalan di depan Baltos serta disepanjang jalan Cikapayang yang disalahgunakan menjadi tempat parkir.

3. Berdasarkan simulasi solusi alternatif untuk meningkatkan kinerja operasi simpang Taman Sari - Cikapayang, diperoleh dua solusi alternatif. Solusi terbaik untuk menyelesaikan masalah panjang antrean serta LoS adalah alternatif kedua yang dapat mengurangi panjang antrean dan meningkatkan LoS E kondisi eksisting menjadi LoS A.

\subsection{Saran}

1. Perlu dilakukan penelitian lebih lanjut mengenai manajemen rekayasa lalu lintas di kawasan Baltos yang melibatkan Jalan Sulanjana serta Jalan Djuanda.

2. Pengambilan data primer seperti volume lalu lintas sebaiknya dilakukan selama satu minggu pada pagi hari, siang hari serta sore hari waktu jam sibuk.

3. Perlu dilakukan penelitian lebih detail mengenai karakteristik pengemudi di Bandung, untuk dapat meningkatkan keakuratan pemodelan, sehingga nilai yang dihasilkan dari software VisSim dapat lebih menyerupai kondisi asli di lapangan. 


\section{DAFTAR PUSTAKA}

1. Everenza, A.B., 2108, Evaluasi Kinerja Operasi Simpang Cihampelas Pasterur dan Simpang Cipaganti-Pasteur dengan Software VisSim, Tugas Akhir Program Studi S-1 Teknik Sipil Universitas Kristen Maranatha, Bandung.

2. Google Earth, 2020.

3. Irawan, M. Z., and Putri, N. H., 2015, Kalibrasi VisSim untuk Mikrosimulasi Arus Lalu Lintas Tercampur pada Simpang Bersinyal (Studi Kasus: Simpang Tugu, Yogyakarta), Jurnal Penelitian Transportasi Multimoda 13 (3): 97-106.

4. Khisty, C.J., and Lall, B., 2006, Dasar-Dasar Rekayasa Transportasi, doi:10.1016/j.ijmedinf.2010.01.008

5. Mbuinga, F. O., 2020, Evaluasi Kinerja Operasi Simpang Dr. Djundjunan-Surya Sumantri Dengan Software Vissim, Jurnal Teknik Sipil 16 (1) : 75-117.

6. Pebriyetti, Widodo, S., Akhmadali, 2018, Penggunaan Software VisSim untuk Analisa Simpang Bersinyal (Studi Kasus: Simpang Jalan Veteran, Gajahmada, Pahlawan dan Budi Karya Pontianak, Kalimantan Barat), Jurnal Mahasiswa Teknik Sipil Universitas Tanjungpura 5 (3): 114.

7. PTV VisSim, url: http://vision-trafic.ptvgroup.com.

8. Susilo, B. H., 2015, Rekayasa Lalu Lintas. Jakarta: Penerbit Universitas Trisakti.

9. Tamin, O.Z., 2000, Perencanaan dan Pemodelan Transportasi, Ed. Kedua, Penerbit ITB.

10. Ulfah, F.D., Purwanti, O., 2019, Analisis Kinerja Persimpangan Jalan Laswi dengan Jalan Gatot Subroto, Kota Bandung Menggunakan PTV VISSIM 9.0, Jurnal Teknik Sipil 5 (3): 74-85. 